\title{
Patient Device Direct Feed Reporting
}

National Cancer Institute

\section{Source}

National Cancer Institute. Patient Device Direct Feed Reporting. NCI Thesaurus. Code C154524.

An indication that vital sign data came from a device in direct contact with the patient. 